\title{
OCEAN COLOUR RADIOMETRY: EARLY SUCCESSES AND A LOOK TOWARDS THE FUTURE
}

\author{
James A. Yoder \\ Woods Hole Oceanographic Institution, Woods Hole MA 02540, USA, Email: jyoder@whoi.edu
}

\begin{abstract}
Satellite ocean colour radiometry (OCR) provides ocean scientists with their only time-dependent view of indices related to ecological and biogeochemical processes at regional to global scales. Beginning with the launch of NASA's Coastal Zone Color Scanner (CZCS) in 1978, imagery from multiple satellite sensors has had a major impact on ocean science and helped establish the importance of ocean biogeochemistry to the major element cycles of the Earth system. OCR is being increasingly used in applications related to societal benefits. Early accomplishments include: improved methods and more accurate calculations of net primary production in the ocean at regional to global scales, including estimates of the relative contributions of land and ocean to net primary production of the biosphere; better understanding of variability of phytoplankton biomass and productivity at regional to global scales and at daily to interannual time scales; better understanding of seasonal phytoplankton dynamics at regional and global scales; better understanding of the impact of major El Niño/Southern Oscillation (ENSO) events and other sources of interannual variability on ocean net primary production and its spatial variations around the globe; intriguing evidence that phytoplankton biomass in the ocean, particularly in the oligotrophic waters in the center of the ocean basins, may be undergoing long term changes; better understanding of the importance of mesoscale mixing processes (eddies, planetary waves) on the distribution of phytoplankton biomass; and initial successes for using OCR imagery to improve fishing efficiency, track harmful algal blooms, provide potential tools for fisheries management, provide products related to water quality assessment and other applications of benefit to society.
\end{abstract}

\section{INTRODUCTION}

Ocean Colour Radiometry (OCR) refers to measurements of the small fraction of sunlight radiance that initially first enters the ocean or other natural water body and is then scattered back across the air-sea interface. The spectra of backscattered radiance, often referred to as water-leaving radiance, differs from the incoming radiance spectra depending on the absorption and scattering properties of natural waters. Thus, comparing the spectra of the incoming and waterleaving radiance yields information on the dominant dissolved and suspended in-water constituents affecting scattering and absorption. Photosynthetic pigments such as Chlorophyll $a$ (abbreviated hereafter as Chl) contained by microscopic phytoplankton are one of the dominant absorbers in open ocean waters, particularly in a broad wavelength band centered in the blue region of the spectra near $440 \mathrm{~nm}$. In the simplest interpretation, the spectra of water-leaving radiance shifts from blue towards green wavelengths as the concentration of phytoplankton (and Chl) increases, thus providing a quantitative way to remotely determine phytoplankton pigment concentration in near-surface waters. Phytoplanktons are the principal photosynthetic organisms in the ocean and thus form the base of upper ocean food webs. Chl is the key pigment involved in photosynthesis (primary production). Satellite measurements of water-leaving radiance, which began with the 1978 launch of the Coastal Zone Color Scanner (CZCS) on NASA's Nimbus-7 spacecraft, provided a new and revolutionary tool for biological oceanographers to study the productivity of the sea and its variability on time and space scales not previously possible.

Before discussing the early successes of satellite OCR, some of the limitations and caveats associated with satellite measurements of OCR need to be pointed out. First, the conditions for applying the simple interpretation of water-leaving radiance mentioned above are not always met. In fact, those conditions are rarely met for coastal waters, as absorption and scattering by other dissolved and suspended substances such as colored dissolved organic matter (CDOM) and suspended sediments often overwhelm the contribution of phytoplankton $\mathrm{Chl}$ to the water-leaving radiance spectra. Second, water-leaving radiance is a small fraction of the radiance entering the water and this comparatively small signal has to travel back through the atmosphere to reach a satellite sensor. The atmosphere also contains gasses and particles that absorb and scatter at the ocean color wavelengths contributing to, and in fact dominating, the upward radiance flux over the ocean. Thus, the atmospheric contributions have to be accurately measured or calculated to allow determination of the relatively weak water-leaving radiance signal, which is at most $10 \%$ of the radiance reaching the satellite sensor at the key wavelengths for algorithms used to calculate $\mathrm{Chl}$ and other in-water constituents. Developing algorithms to quantify the different constituents of complex coastal 
waters as well as to improve methods to separate the water-leaving radiance signal from the total radiance reaching a satellite sensor still present significant challenges and are areas of active research. Third, satellite and other measurements of OCR above the surface of the water integrate water-leaving radiance over about 1 optical depth (defined as $1 / \mathrm{K}$, where $\mathrm{K}$ is the radiance attenuation coefficient with units of $\mathrm{m}^{-1}$ ). That depth depends upon water clarity and ranges from as deep as $30-50 \mathrm{~m}$ in the open ocean to less than $1 \mathrm{~m}$ in turbid coastal waters. As a result, satellite OCR measurements do not yield information on in-water constituents below the first optical depth. A common assumption is that satellite OCR measurements represent conditions in the mixed layer. Finally, satellite OCR sensors cannot image through clouds.

Figure 1 illustrates the measurement wavelengths of the SeaWiFS (Sea-viewing Wide Field of View Sensor) sensor - a sensor of particular importance for ocean color research and applications given its long record of continuous measurements extending from September, 1997, to the present (2010, although data drop-outs are now common), and because SeaWiFS data has been extremely well calibrated. Six of the measurements are made at narrow wavelength bands (bands 1-6) in the
400 to $700 \mathrm{~nm}$ range and 2 are in the near IR, and all have a pixel resolution of about $1 \mathrm{~km} \mathrm{X} 1 \mathrm{~km}$. The nearIR bands (bands 7 and 8) are used to help calculate the atmosphere's contribution to satellite radiances at all wavelengths. Water-leaving radiance from ocean waters seaward of the coastal zone is undetectable at near-IR wavelengths, and thus all of the measured radiance is due to light backscattered from atmospheric constituents. Thus, measurements at these wavebands provide insight on the variable absorbing and scattering components (mostly aerosols) of the atmosphere. Simple algorithms for calculating Chl concentration are based on ratios involving bands 2,3 , or 4 with band 5 [18]. More sophisticated algorithms are based on inversion techniques and use bands $1-6$ to simultaneously calculate $\mathrm{Chl}$ and other constituents [23]. Advanced sensors, such as MERIS (Medium Resolution Imaging Spectrometer) which was launched in 2002 on ESA's ENVISAT (European Space Agency/Environmental Satellite) satellite, have more spectral bands and the data are processed using neural networks and other sophisticated inversion techniques [9]. The high spectral resolution of MERIS, along with its $300 \mathrm{~m} \mathrm{X} 300 \mathrm{~m}$ pixel resolution, makes its data particularly useful for imaging complex coastal waters.

\section{Sensor Wavelengths for SeaWiFS}

\begin{tabular}{|c|c|c|}
\hline Band Number & Wavelength $(\mathrm{nm})$ & \multicolumn{1}{|c|}{ Purpose } \\
\hline 1 & $402-422$ & Colored Dissolved Organic Matter \\
\hline 2 & $433-443$ & Phytoplankton Pigments $(\mathrm{eg} \mathrm{Chl} \mathrm{a)}$ \\
\hline 3 & $480-490$ & Phytoplankton Pigments $(\mathrm{eg} \mathrm{Chl} \mathrm{a)}$ \\
\hline 4 & $500-520$ & Phytoplankton Pigments (eg Chl a) \\
\hline 5 & $545-565$ & Back Scatter - Particulate Carbon \\
\hline 6 & $660-680$ & CZCS Heritage and Back Scatter \\
\hline 7 & $745-785$ & Atmospheric Correction \\
\hline 8 & $845-885$ & Atmospheric Correction \\
\hline
\end{tabular}

Note: Additional spectral bands, e.g. on MERIS, yield improved algorithms and new products.

Figure 1. Wavelength bands for the SeaWiFS OCR sensor and a brief description of how the various bands are used in the processing algorithms. 


\section{SCIENTIFIC APPLICATIONS}

Resolving the variability of key biogeochemical and ecological indices related to ocean productivity at mesoto basin-scales, and at time scales ranging from days to interannual, is the key science driver for satellite OCR missions. Time series of OCR imagery are the only routinely acquired measurements related to ecological and biogeochemical processes available to ocean scientists at these time and space scales. For example, no in situ measurement platforms are currently deployed to provide global biological or chemical data equivalent to the physical measurements provided by Argo (Array for Real-time Geostrophic Oceanography) floats.

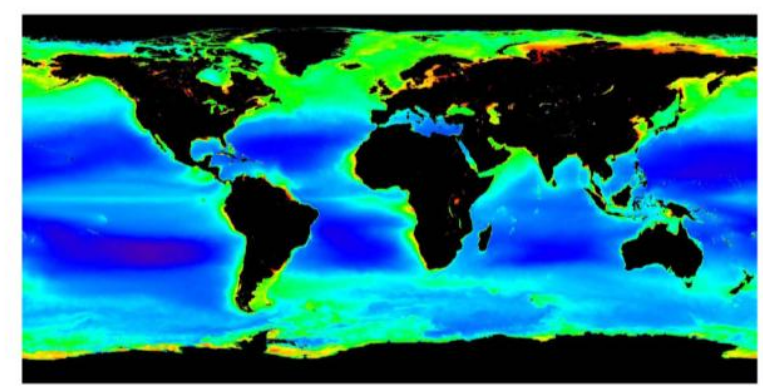

Figure 2. Composite SeaWiFS Chl image from 19972009. Image courtesy of G.C. Feldman of the NASAGSFC (National Aeronautics and Space

Administration/Goddard Space Flight Center) (http://oceancolor.gsfc.nasa.gov/).

\subsection{Global Productivity}

Figure 2 is a global composite SeaWiFS Chl image from the first 12 years of data collection. The image shows comparatively high $\mathrm{Chl}$ concentrations in ocean margin waters including the major upwelling systems of the California Current, off northwest Africa, off the Peru/Chile coasts, and in the Arabian Sea. The effect of upwelling along the Equator in the Atlantic and particularly in the Pacific leaves a strong signal, as do the plumes of major rivers such as the Amazon and Orinoco, which extend well offshore into the Atlantic and Caribbean, respectively. High mean Chl concentrations at latitudes poleward of ca. 40 degrees compared to the comparatively low concentrations in subtropical ocean basins are a result of seasonal phytoplankton "blooms". These blooms are caused by the supply of nutrients from winter mixing, then followed by spring stratification and seasonal increases in solar irradiance. Those conditions stimulate phytoplankton productivity leading to high spring and summer Chl.
Incorporating global maps of $\mathrm{Chl}$ derived from satellite OCR imagery into calculations of regional to global primary production was one of the most important early successes. Before satellite data were available, estimates of global ocean primary production based on in situ data differed by factors of up to 5-10X. To a good first approximation, ocean photosynthesis (primary production) can be calculated from maps of $\mathrm{Chl}$ concentration, incident solar irradiance plus some additional physiological parameters derived from measurements [20]. Satellite calculations using different methods and assumptions tend to agree within 10-20\% owing to the importance and dominance of Chl in the calculation (and thus the importance of the satellite data for these calculations). A key finding from calculations based on satellite data is that ocean and terrestrial net primary production contribute more or less equally to global production [10].

\subsection{Seasonal to Interannual Variability}

Fig. 2 of course does not capture Chl variability in space and time, and quantifying that variability is one of the primary scientific applications of satellite OCR [37]. Time series of satellite OCR have been used in many studies of seasonal processes at regional, basin and global scales. Figure 3 illustrates the time and space variability of a 7-year time series of global SeaWiFS Chl imagery covering the ocean from $50 \mathrm{~N}$ to $50 \mathrm{~S}$ latitudes [37]. The significant finding is the very coherent pattern across the basins and the regularity of the seasonal "beat". As expected from seasonal changes in incident solar irradiance essential to photosynthesis, the patterns in the two hemispheres are similar but 6 months out of phase. For both hemispheres, peak Chl concentrations occur during winter months in subtropical latitudes (ca. 20-40 deg), whereas peak concentrations occur later in spring and summer at higher latitudes (following stratification).

One of the early applications for OCR image time series was better quantification and understanding of seasonal cycles at regional scales (ca. 1000-km) in many parts of the global ocean. Regional time series have been analyzed for ocean margin, marginal seas and ocean basins from many locations in the global ocean. Examples below show how analyses of regional imagery, supported by in situ data and other information, allows one to sort out the different physical forcings and their respective effects on seasonal $\mathrm{Chl}$ cycles. The imagery helped describe the important dynamics in different regimes and helped demonstrate regional similarities and differences around the global ocean. 
Off the East Coast of North America, for example, OCR imagery showed how regional differences in phytoplankton bloom characteristics are related to seasonal changes to incident solar irradiance and stratification. Winter Chl peaks occur in comparatively shallow shelf waters ( $<50 \mathrm{~m}$ depth) at mid latitudes (ca. $35^{\circ}$ to $45^{\circ} \mathrm{N}$ ), since the depth of mixing is constrained by bottom depth, and solar irradiance is sufficiently high even during winter to sustain growth [27, 28, 38 and 39]. This is not the case, however, for deeper slope and basin waters and for higher latitudes (e.g. Gulf

EOF 1: $36.6 \%$

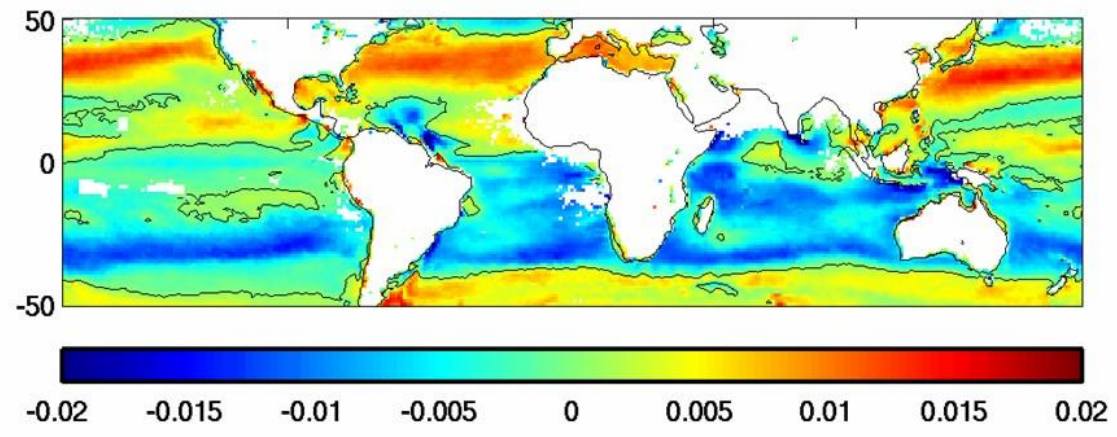

Amplitudes for Mode 1

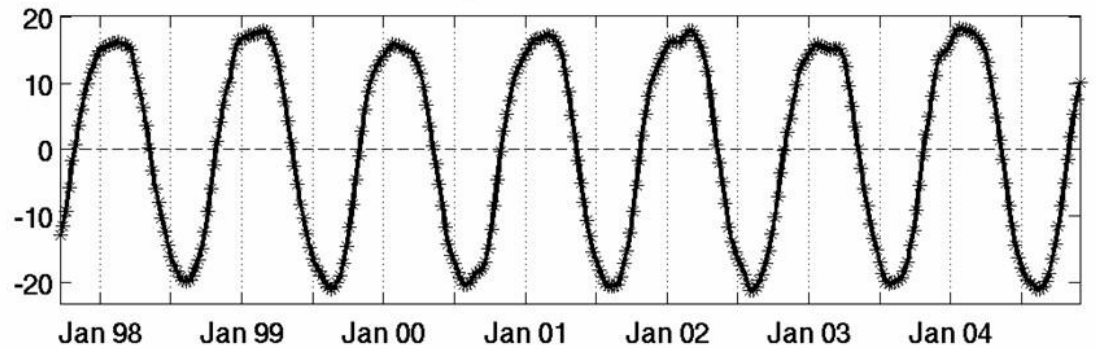

Figure 3. Results of an EOF (empirical orthogonal function) analysis on a 7-year time time-series of 8-day resolution global SeaWiFS Chl images (50N to 50S latitude) from which the 7-year mean Chl image was first subtracted. The results show that Mode 1, which is dominated by the seasonal signal, accounts for about $37 \%$ of the total variability of the time series. For any time and for any pixel, the signed magnitude of the deviation from the seven-year mean Chl is the product of the amplitude value in the time series (lower panel) and the pixel value in the spatial pattern (upper panel). From [37].

of St. Lawrence). In these regions, seasonal blooms do not occur until stratification shoals the mixed layer, and that process occurs in spring-early summer depending on latitude. Chl imagery of other parts of the global ocean shows patterns similar to those observed along the East Coast of North America. At the mid latitudes of the East Sea/Japan Sea [35 and 41] and the Mediterranean Sea [5], seasonal Chl patterns for shallow versus deeper waters are similar to those observed off the U.S. East Coast. In contrast, seasonal Chl variations are synchronous throughout the basin at the comparatively low latitudes $\left(<30^{\circ} \mathrm{N}\right)$ of the Gulf of Mexico with peak concentrations occurring from December to February, i.e. when mixing (and thus nutrient flux) is strongest as evidenced by the depth of the mixed layer [16]. Lowest $\mathrm{Chl}$ concentrations in the
Gulf of Mexico occur from May to July when the water column is most stratified [16].

At tropical latitudes, Chl concentrations tend to be low and generally with no seasonal cycle except under unusual circumstances [30]. Using SeaWiFS imagery and in situ measurements of chlorophyll $a$, [30] observed a $>3 \mathrm{X}$ enhancement of $\mathrm{Chl}$ (and in situ chlorophyll a) concentrations in winter compared to summer in the northern South China Sea $\left(18^{\circ} \mathrm{N}, 116^{\circ}\right.$ E). Areas of unusually high $\mathrm{Chl}$ in the oligotrophic North Pacific subtropical gyre (near $30^{\circ} \mathrm{N}, 150^{\circ} \mathrm{W}$ ) were observed in SeaWiFS Chl imagery in 3 out of 6 years of SeaWiFS coverage and 4 out of 7 years of CZCS coverage [33]. These summer anomalies were not associated with sea surface height $(\mathrm{SSH})$ nor sea surface temperature (SST) anomalies, and thus were probably not related to mixing by eddies or some other 
physical process. A possible explanation is that the blooms were related to nitrogen supplied by Trichodesmium (a phytoplankton genera that can fix elemental N) [33]. The latter study demonstrates that there are seasonal features, at least during some years in the North Pacific, not readily explained by conventional models of seasonal dynamics. Furthermore, satellite imagery was the key data source leading to the discovery of these unusual features.

Coastal upwelling has dramatic effects visible in OCR imagery. Three years of SeaWiFS imagery and wind fields derived from satellite scatterometer measurements were used to compare $\mathrm{Chl}$ and upwelling-favorable wind patterns in the 4 major eastern boundary currents: California, Canary, Peru-Chile and Benguela Currents [26]. CZCS data was particularly sparse for the southern hemisphere $(\mathrm{SH})$ upwelling systems and thus SeaWiFS imagery provided the first good opportunity for comparing satellite $\mathrm{Chl}$ seasonal patterns for these 4 systems. Of the 4 upwelling systems, highest mean $\mathrm{Chl}$ concentrations (>5 mg m-3) within $100 \mathrm{~km}$ of the coast occurred off northwest Africa (Canary Current) from ca. $8-17^{\circ} \mathrm{N}$ latitude. Except for the Iberian Peninsula (Canary Current), mid latitude $\mathrm{Chl}$ seasonal maxima occurred in spring and summer coinciding with seasonal maxima in upwelling [26 and 29]. At lower latitudes (except for the Canary Current), high $\mathrm{Chl}$ concentrations were not coincident with upwelling favorable winds. The proposed explanation for this lack of coherence at low latitudes is that $\mathrm{Chl}$ concentrations there are also affected by equatorial current systems, surface heat fluxes, and distant forcing along the equatorial wave guide [26]. In the Cariaco Basin, the seasonal cycle in Chl generally tracked seasonal upwelling associated with the trade winds. Plumes of upwelled waters (defined by colder water and Chl $>0.4 \mathrm{mg} \mathrm{m}^{-2}$ ) within the basin covered an area in excess of $10^{4} \mathrm{~km}^{2}$ during each of 6 years of SeaWiFS coverage [17].

\subsection{ENSO and low frequency variability}

The ENSO event that began in 1997 caused dramatic changes in the global ocean, and for the first time, satellite observations were able to quantify the impact of a large ENSO event on the productivity of the global biosphere. Figure 4 shows the change in ocean and land vegetation and the calculated impact on net primary production of the biosphere during the transition from the El Nino phase to the La Nina phase during the large ENSO event that began in 1997. The results show that
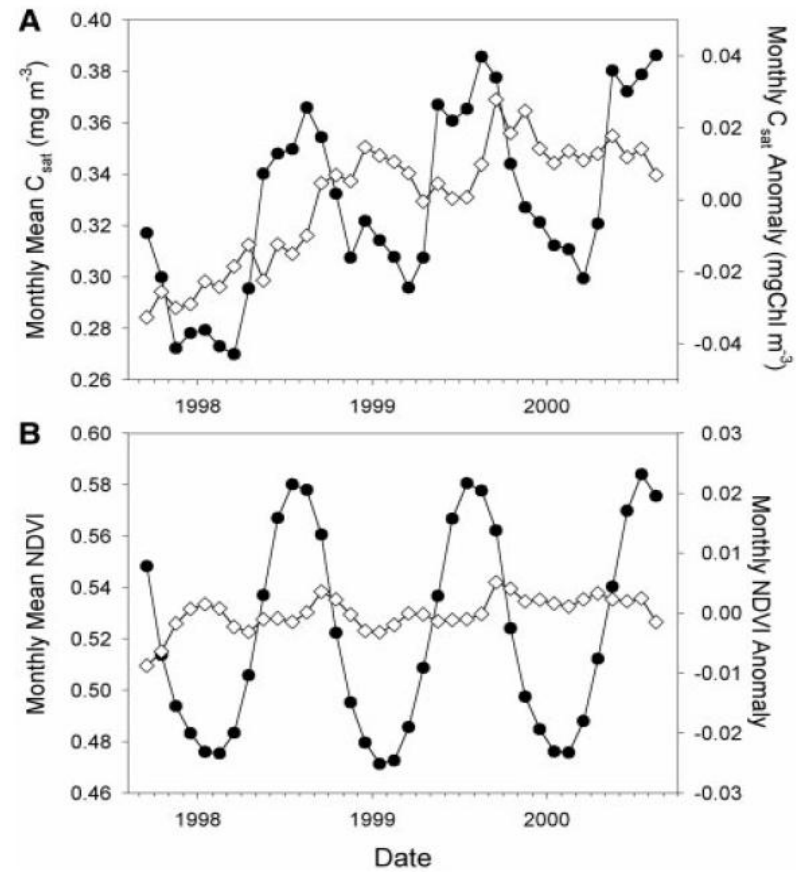

Figure 4. Productivity change during an ENSO transition. A. Ocean - SeaWiFS Chl. B. Land-SeaWiFS vegetation index. In both $(A)$ and $(B)$, global monthly means are indicated by black circle and anomalies by open diamonds. Changes in ocean and land vegetation during the transition led to a global productivity increase of $6 \mathrm{Pg} /$ year, with most of the response in the ocean. From [3].

global primary production changed by about $6 \mathrm{Pg} /$ year during the transition (equivalent to about $6 \%$ of the total global productivity) with most of the response from the ocean [3].

One of the most important scientific contributions of long time series of OCR imagery is and will be to help quantify inter-annual variability in the productivity of marine ecosystems and to separate the effects of interannual forcing (e.g. by ENSO) from trends caused by changing climate or other human impacts. Five recent manuscripts [2, 4, 11, 22 and 32] indicate that significant $\mathrm{Chl}$ trends, both increases and decreases, are observed in various regions of the world's oceans during the past decade, but with the most significant trend being a general decrease of $\mathrm{Chl}$ in the mid-ocean gyres (Fig. 5). Some suggest climate change effects on ocean stratification as a possible explanation, since warming would increase stratification, which would decrease nutrient flux to surface waters. However, 4 of the 5 manuscripts are based on time series that began in fall, 1997, with the launch of SeaWiFS. Thus, these 
time series were initiated during the beginning of one of the largest ENSO events of the century. Other studies [34, 36 and 37] showed that both the El Nino and La Nina phase of that ENSO event had significant impacts on satellite-derived $\mathrm{Chl}$ in many regions of the global ocean. The effects were evident in satellite OCR anomalies for several years, including high chlorophyll anomalies in the La Nina phase, which began in 1998. A recent manuscript [15] was able to analyze parts of the CZCS and SeaWiFS records along with SST time series to study decadal changes. The results show a "basin-scale response of phytoplankton to large-scale climate oscillators." The study also concluded that "averaging over several decades may eventually reveal longer-terms trends related to subtle changes in physical forcing" [15]. How many decades of data will be required? Based on a comparison of models and satellite data, some have concluded that 40 years of observations will be required to sort out the effects of ENSO, NAO (North Atlantic Oscillation) and other low frequency phenomena from possible trends related to a changing climate and changing ocean [12].

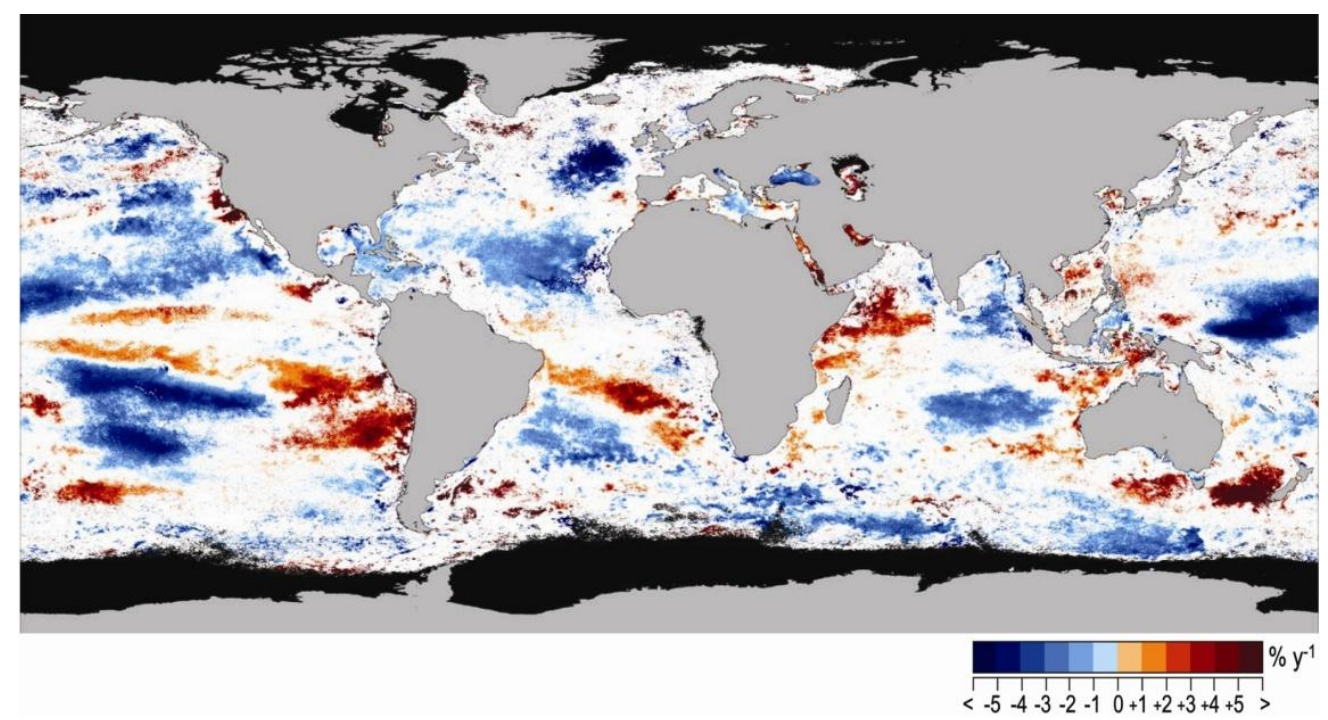

Figure 5. Evidence suggesting long-term trends in a 10-year record of SeaWiFS global imagery. Colors indicate areas of the ocean that are either decreasing (blue) or increasing (green and red) over the 10-year record. From [32].
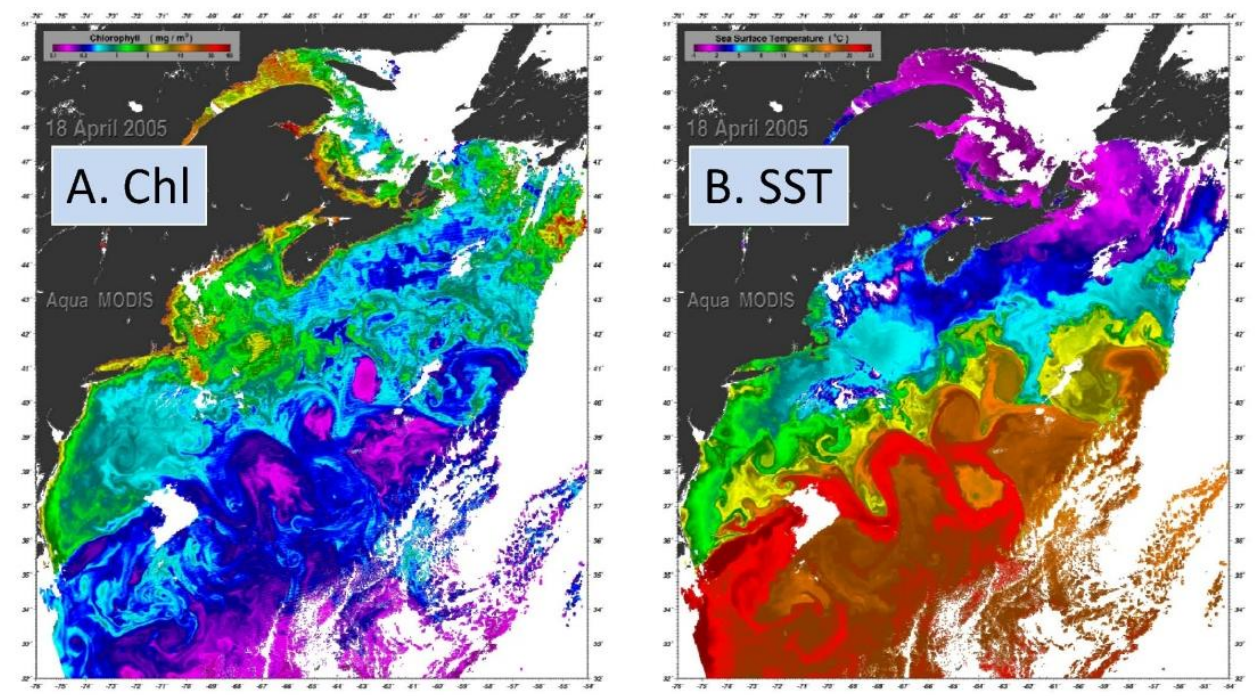

Figure 6. MODIS Aqua image showing Chl and SST fields off the northeast coast of the U.S. Gulf Stream meanders and eddies are evident in the imagery and the features are generally replicated in the 2 images with higher Chl associated with colder waters. For Chl, high concentrations are red and yellow, whereas low concentrations are blue. For SST, colder waters are blue and warmer are red. Courtesy NASA-GSFC. 

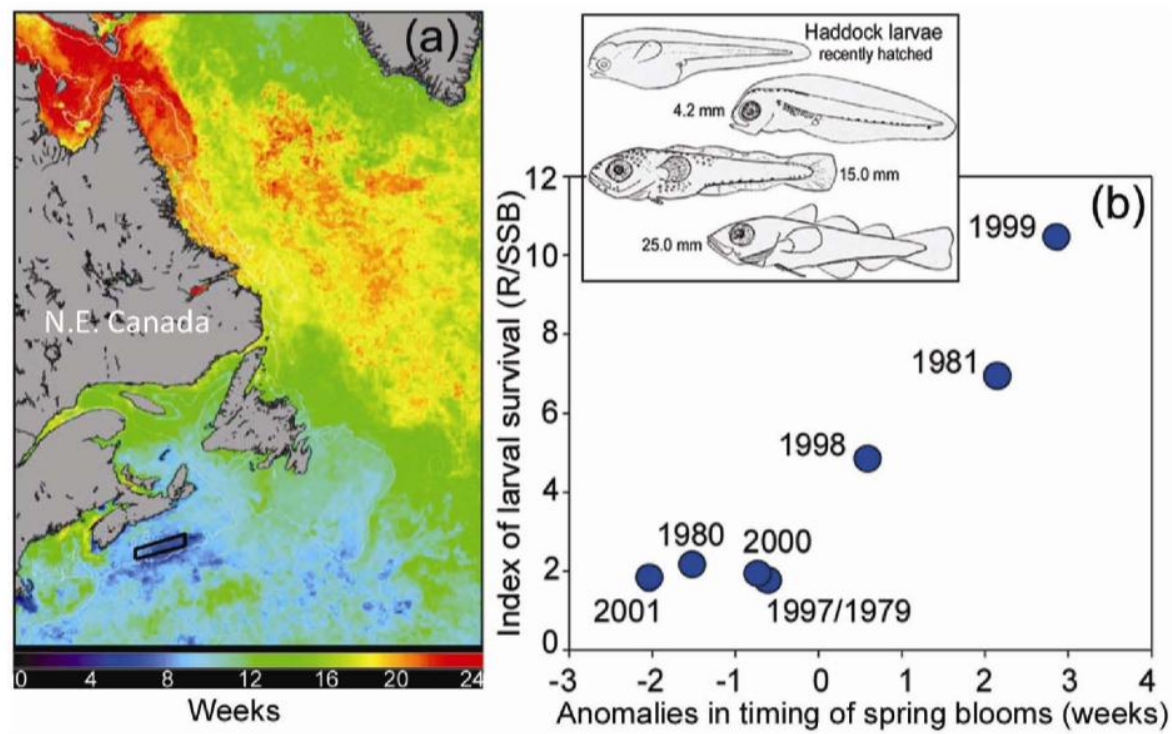

Figure 7. Survival index of larval haddock versus anomalies in the timing of the spring phytoplankton bloom as measured in satellite OCR imagery (b) for a study area off Nova Scotia, Canada (a). Modified from [21]

\subsection{Mesoscale Distributions}

Figure 6 shows concurrent SST and Chl fields as determined by MODIS-Aqua (Moderate Resolution Imaging Spectroradiometer- EOS PM (Earth Observing System-afternoon equatorial crossing time). This image pair, and many other images like it, show eddies and other complex mesoscale structures in the surface ocean evident in both physical (SST) and biological (Chl) fields, as well a high inverse correlation (high Chl, low SST) of the features in both. Comparing OCR and SST imagery from the California Current [1], near the Gulf Stream [6] and at other locations led to the now obvious conclusion as to the importance of mesoscale mixing processes in affecting biological distributions. These images helped stimulate interest in understanding the impact of ocean eddies on biological productivity eventually leading to major field programs designed to test hypotheses as to the significance of eddy mixing to upper ocean nutrient budgets.

Animations of $\mathrm{Chl}$ image sequences generally show westward propagation of features that suggest eddy or wavelike motions. In contrast to satellite measurements of sea surface height (SSH), however, OCR image time series at daily temporal resolution for more than just a few days are almost impossible to acquire owing to cloud coverage. Thus, it is virtually impossible to analyze OCR imagery at the time and space scales required to generate statistics comparable to those that can obtained by analyzing SSH fields. With some time and space averaging, however, it was possible to demonstrate Rossby wave-like movement of Chl features in OCR imagery and to explain much of the variability evident in the animations [7 and 31]. These observations led to ongoing discussions as to why Rossby waves would have a Chl signature. Some suggested that time and space averaging required to build up a time series from cloud-contaminated imagery had smeared out what were actually westward propagating ocean eddies. Regardless of the correct interpretation, eddies versus Rossby waves, the key finding of the two studies mentioned above is that the patterns observed in animations of OCR imagery were not random but were organized features that can be explained by known physical processes.

\section{SOCIETAL BENEFITS OF OCR}

OCR imagery has made an immense contribution to the research community in their efforts to understand ocean ecosystems and ocean biogeochemistry, but practical and commercial applications have been slow to develop. This was in part owing to the initial difficulty of processing and distributing the data, but now algorithms and computer technology have caught up. New applications for fisheries, fisheries management, hazard assessment (in particular, harmful algal blooms), water quality assessment and other societal benefits are now rapidly developing. The societal benefits of OCR imagery were recently summarized in a report of the International Ocean Colour Coordinating Group [13].

One dramatic success is the use of data from the OCM ocean colour sensor on the Indian Space Research Organization (ISRO) IRS-P4 satellite to map features in 
the Indian Ocean associated with fish schools of commercial interest. Using OCM imagery to efficiently locate fish schools saved enough money in fishing boat fuel costs alone to justify ISRO launching a second and replacement sensor in 2009.

Figure 7 illustrates a fisheries management application of OCR imagery. The figure shows the relationship between larval haddock survival and anomalies in the timing of the spring bloom in shelf waters off Nova Scotia [21]. Survival of larval fish is generally believed to be a key step for determining the year-class strength of commercial fisheries. The data illustrated in Fig. 7 provide supporting evidence for a well-known paradigm in fisheries biology called the "match-mismatch" hypothesis. In brief, the timing of the spring phytoplankton bloom has to match the spawning time for larval fish to ensure high rates of larval fish survival. The data in the figure indicates that comparatively late spring blooms are beneficial to larval fish. This study demonstrates the possibility of using OCR imagery to predict year-class strength for this particular fishery. It also opens the possibility of using similar analyses to predict year-class strength of other commercial fish species, and thus this approach could prove to be an important fisheries management tool for the future.

Satellite OCR measurements are being used to help provide advance warning of harmful algal blooms (HABs) [19 and 24]. For example, NOAA (National Oceanic and Atmospheric Administration) is operating a warning system for the eastern Gulf of Mexico (Florida coast) characterized by frequent $\mathrm{HABs}$ that have an adverse effect on the economically important tourist industry and on the shellfish industry. OCR data cannot distinguish HABs from other types of phytoplankton blooms. However, experience gained from many years of research alerts those involved with the program when features are observed in OCR imagery that have been associated with past HAB blooms. HAB blooms can then be confirmed by in situ samples collected by ships directed to specific locations using the satellite imagery as a guide. The results of the forecasts are provided to local coastal resource managers who use the information to prepare for, or implement, beach closures or to take other mitigation measures [25].

The higher spatial resolution (300m x 300m pixels) and spectral resolution of MERIS compared to coarser resolutions of SeaWiFS, MODIS and other global OCR sensors led to increasing interest in OCR imagery for water quality applications in coastal and inland waters [13]. One approach for using OCR data for water quality applications is to feed concurrent satellite and in situ measurements into reflectance modelling algorithms to generate products such as water clarity, total suspended matter and dissolved organic matter in addition to Chl that provide information on eutrophication, physical disturbance and contamination.
Assimilating these products into appropriate models helps inform those responsible for managing coastal and inland waters [13].

\section{LOOKING TO THE FUTURE}

Many space agencies are planning satellite OCR missions for the future. Sensor specifications and modes of operations can be quite different for the future sensors depending on the specific application: coastal versus open ocean; repeat coverage of a single area versus global coverage; high spectral resolution versus a comparatively simple and inexpensive band set and so on. No single agency, or country for that matter, can afford to do everything well. International cooperation is thus extremely important to efficiently serve international researchers and those using the data for management and other applications. Furthermore, achieving international consensus on algorithms and other key processing details will be difficult. This implies that the best approach is to provide open access to raw satellite data as well as the in situ validation data sets used to modify at-launch calibration. Making raw data and calibration information freely available provides the opportunity for researchers to implement multiple algorithms and to test their respective effectiveness for specific applications.

Most space agencies involved with OCR sensors are planning to cooperate through the activities of the Ocean Color Radiometry Virtual Constellation (OCRVC) [40] which was organized through the international Committee on Earth Observation Satellites (CEOS). One important purpose of the OCR-VC is to ensure a long-term, sustained record of calibrated satellite ocean colour radiances (OCR) at key wavelength bands to determine the impact of ocean climate signals and climate change on ocean ecosystem and biogeochemical parameters. The strategy of the OCR-VC is to produce calibrated OCR measurements so that the data are consistent from multiple satellites. A second goal is to encourage merging the data from multiple sensors to improve global ocean spatial coverage. SeaWiFS, MODIS-Aqua, MODIS-Terra, MERIS and ISRO's OCM-2 (launched in 2009) are currently in operation, and ESA, NOAA/NASA, and JAXA have firm plans for new launches of OCR instruments within the next few years. All of these sensors have somewhat different specifications, calibration strategies and other differences which point to the importance of an international cooperative program to ensure that a continuous and calibrated record can be sustained across mission lifetimes. China also has ambitious plans for launching ocean observing satellites, some of which will make OCR measurements, beginning in 2011. Brazil and Argentina are developing plans for a cooperative OCR mission with a possible launch in 2015. The OCR-VC is currently a federation of agencies each 
supporting their own activities. An important next step could be a coordinated international effort for a processing and analysis center supported by multiple agencies similar to what is currently in place for SST, altimetry and for Argo. Prototypes for an international effort include national programs such as NASA's SIMBIOS (National Aeronautics and Space Administration's Sensor Intercomparison for Marine Biological and Interdisciplinary Ocean Studies) (http://www.ioccg.org/reports/simbios/simbios.html) and ESA's GlobColour (European Node for Global Ocean Colour) programs (http://www.globcolour.info/).

Sustaining a long-term record of calibrated OCR for a limited number of wavelength bands is an important goal. In addition, advanced instruments, new approaches, and new applications are being developed and refined, and a few examples are described below.
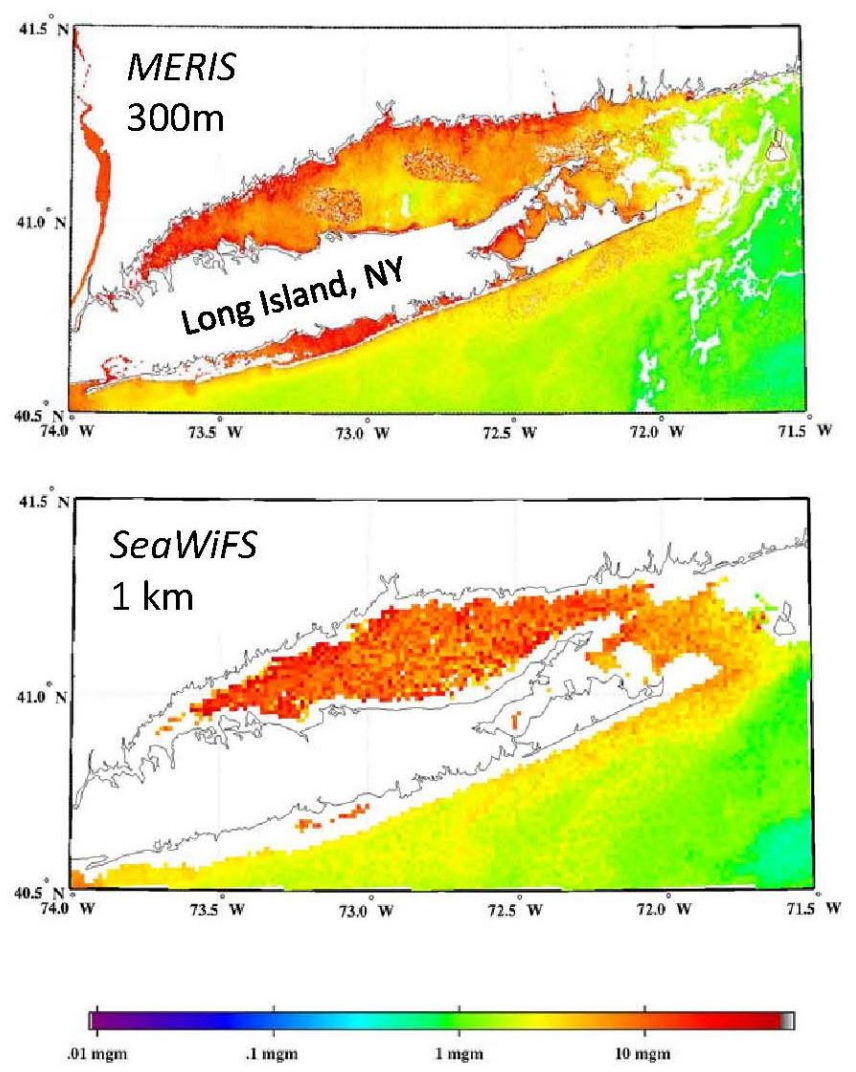

Figure 8. MERIS full spatial resolution $(0.3 \mathrm{~km} X 0.3$ $\mathrm{km}$ pixels) Chl image (upper panel) and a full spatial resolution (1 km X $1 \mathrm{~km}$ pixels) SeaWiFS Chl image

from the same day. Note that coastal features, e.g. river plumes, are evident in the MERIS image whereas they are not resolved in the SeaWiFS image. Courtesy NASA-GSFC and ESA.

\subsection{Higher Spatial Resolution}

Full resolution MERIS imagery has $300 \mathrm{~m} \mathrm{X} \mathrm{300m}$ pixels and approximately $2 \mathrm{X}$ the number of spectral bands as, for example, SeaWiFS or MODIS-Aqua. The daunting task of processing full resolution data has delayed general access to the complete MERIS full resolution data set, but a new ESA-sponsored program, CoastColour (http://www.coastcolour.org/) plus more open real-time access to the direct broadcast data, will produce a major new data set for the coastal ocean. For example, CoastColour will process more than 20,000 full resolution scenes from the MERIS archive going back to 2002. The goal of the project is to increase global users by developing, demonstrating and validating the latest techniques for monitoring water constituents in coastal zones around the world. Fig. 8 demonstrates the potential impact of higher spatial resolution imagery to support coastal and marine applications. Note that many coastal features are evident in the MERIS full resolution image than are observed in the coarser imagery of SeaWiFS. Pixel resolution comparable to MERIS is planned for the Ocean and Land Colour Instrument (OLCI) (http://www.esa.int/esaLP/SEMTST4KXMF_LPgmes_ 0.html) on ESA's Sentinel 3a and 3b missions with 3a to be launched in 2013. ESA anticipates overlap of MERIS and OLCI coverage which will mean a continuous source of high spatial resolution imagery extending from 2002 into the future. The OCM-2 instrument launched on ISRO's Oceansat-2 late in 2009 has similar spatial resolution.

\subsection{New Data Products}

The most common data products currently produced from satellite OCR data by relatively simple empirical algorithms are $\mathrm{Chl}$ or using a similar algorithm, the diffuse attenuation coefficient (K). Other products are possible using inversion techniques and other more complex algorithms applied to OCR spectra. Coloured organic matter, which is a mixture of coloured dissolved organic matter (cdom) as well as particulate marine detritus, is now a commonly produced product, as is a measure of particle backscatter. The latter is used by some to calculate particulate carbon or suspended sediment. A simple measure of cell size and simple indices of phytoplankton type are also in development with some encouraging recent results. These and other new data products will be in common use within a few years opening up new applications for OCR imagery.

\subsection{OCR from Geostationary Orbit}

OCR instruments in geostationary orbit present possibilities for new applications, as multiple images of the same ocean surface are possible during a single day, perhaps as frequently as 1 scene per hour. Korea will launch the first ocean colour instrument in geostationary orbit (Geostationary Ocean Color Imager or GOCI) in 
2010. GOCI will collect sequential imagery from a $500 \mathrm{~km}$ X $500 \mathrm{~km}$ study area selected within a $2500 \mathrm{~km} \mathrm{X}$ $2500 \mathrm{~km}$ grid over the East and South China Sea producing about 1 scene per hour with $500 \mathrm{~m}$ X 500m pixel resolution and a signal-to-noise ratio in the ocean color bands that is sufficiently high to implement ocean colour algorithms. Scientific and operational applications from geostationary orbit include: sediment transport estimates including tidal effects, monitoring and tracking of harmful algal blooms, ecosystem impacts of tidal forcing, diurnal cycling of optical properties in open ocean waters, and biological-physical coupling at meso and sub-meso scales.

\subsection{BioArgo and bio-optical measurements from other autonomous platforms}

Argo (http://www.argo.net/) has proven to be an immensely successful in situ program and an important complement to satellite altimetry measurements. The combination of altimetry and global density profiles provide physical oceanographers with a revolutionary tool for observing the 3-D, time dependent state of the ocean. Ocean scientists are exploring the potential of Argo floats, gliders and other autonomous vehicle platforms for bio-optical and chemical measurements that can complement satellite OCR measurements by, for example, adding the vertical dimension to the 2-D satellite fields. Prototypes for BioArgo have been developed and successfully tested. Although the significant technical challenges are overcome, there is yet no community consensus as to the minimum instrument complement for BioArgo, so full implementation is not yet possible but could occur in the near future [8].

\subsection{Dynamic Green Ocean Models (DGOMs)}

DGOMs (Dynamic Green Ocean Models) are biogeochemical models that include the distinct biogeochemical functions of different classes of plankton. They are used to study the feedbacks between ocean biogeochemistry and ocean changes caused by climate change. The new data products from satellite OCR mentioned above in this section will be a source of data to initiate and validate DGOMs [14].

\section{CONCLUSIONS}

Satellite OCR sensors provide a new and revolutionary tool for studying marine ecosystems and marine biogeochemistry. The fact that approximately $50 \%$ of the global primary production occurs in the ocean and is cycled through marine ecosystems attests to the importance of sustained satellite OCR measurements for the study of global carbon and other element cycles and to understand the impacts of climate change to the Earth system. The data are now in wide use by researchers around the world and the user base, including those involved in applications related to societal benefit, is developing rapidly. Some of the key successes include better estimates of net primary production at regional to global scales; better understanding of ocean variability at time scales of days to interannual and spatial scales from ca. $1 \mathrm{~km}$ to the global ocean particularly in reference to ecological and biogeochemical variables; importance of ocean eddies and/or planetary waves affecting mesoscale variability of ecological and biogeochemical variables; some initial insights into what could be long-term trends in the ocean, particularly the possibility that phytoplankton biomass may be declining in the surface waters of the ocean basins; and applications related to water quality, fisheries and other societal benefits.

\section{REFERENCES}

1. Abbott, M.R. and P.M. Zion. 1987. Spatial and temporal variability of phytoplankton pigment off northern California during coastal ocean dynamics experiment 1 . J. Geophys. Res. 92: 1745-1755.

2. Antoine, D., A. Morel, H.R. Gordon, V.F. Banzon and R.H. Evans. 2005. Bridging ocean color observations of the 1980s and 2000s in search of long-term trends. $J$. Geophys. Res., 110, C06009, doi:10.1029/2004JC002620.

3. Behrenfeld, M.J., J.T. Randerson, C.R. McClain, G.C. Feldman, S.O. Los, C.J. Tucker, C.J., P.G. Falkowski, C.B. Field, R. Frouin, W.E. Esaias, D.D. Kolber and N.H. Pollack. 2001. Biospheric primary production during an ENSO transition. Science 291 (5513): 2594 2597.

4. Behrenfeld, M.J., R.T. O'Malley, D.A. Siegel, C.R. McClain, J.L. Sarmmiento, G.C. Feldman, A.J. Milligan, P.G. Falkowski, R.M. Letelier and E. S. Boss. 2006. Climate-driven trends in contemporary ocean productivity. Nature 444, doi:10.1038/nature05317.

5. Bosc, E.; Bricaud, A.; Antoine, D. 2004. Seasonal and interannual variability in algal biomass and primary production in the Mediterranean Sea, as derived from 4 years of SeaWiFS observations. Global Biogeochem. Cycles, Vol. 18, No. 1, GB1005, doi:10.1029/2003GB002034.

6. Brown, O.B., Evans, R.H., Brown, J.W., Gordon, H.R., Smith, R.C. and Baker, K.S. (1985). Phytoplankton blooming off the U.S. East Coast: a satellite description. Science, 229: 163-167.

7. Cipollini, P., D. Cromwell, P.G. Challenor and S. Raffaglio. 2001. Rossby waves detected in global ocean colour data. Geophysical Research Letters 28: 323-326.

8. Claustre, H. \& Co-Authors (2010). "Bio-Optical Profiling Floats as New Observational Tools for Biogeochemical and Ecosystem Studies: Potential Synergies with Ocean Color Remote Sensing." in these proceedings (Vol. 2), doi:10.5270/OceanObs09.cwp.17. 
9. Doerffer, R. and Schiller, H. (2007). The MERIS Case 2 water algorithm. International Journal of Remote Sensing, 28: 517-535

10. Field, C.B., M.J. Behrenfeld, J.T. Randerson and P. Falkowski. 1998. Primary production of the biosphere: integrating terrestrial and oceanic components. Science 281 (5375) 237-240

11. Gregg, W.W., N.W. Casey and C.R. McClain. 2005. Recent trends in global ocean chlorophyll, Geophys. Res. Lett. 32, L03606, doi:10.1029/2004GL021808.

12. Henson, S.A., J.L. Sarmiento, J.P. Dunne, L. Bopp, I. Lima, S.C. Doney, J. John and C. Beaulieu. 2010 Detection of anthropogenic climate change in satellite records of ocean chlorophyll and productivity. Biogeosciences 7: 621-640.

13. IOCCG 2008. Why ocean colour? The societal benefits of ocean-colour technology. Platt, T., Hoepffner, N. Stuart, V. and Brown, C. (eds.), Reports of the International Ocean-Colour Coordinating Group, No. 7, IOCCG, Dartmouth, Canada.

14. Le Quéré, C. \& Co-Authors (2010). "Observational Needs of Dynamic Green Ocean Models" in these proceedings (Vol. 2), doi:10.5270/OceanObs09.cwp.56.

15. Martinez, E., D. Antoine, F. D'Ortenzio and B. Gentili. 2009. Climate-driven basin-scale decadal oscillations of oceanic phytoplankton. Science 326, 1253, doi:10.1126/science.1177012.

16. Muller-Karger, F.E., J.J. Walsh, R.H. Evans and M.B. Meyers. 1991. On the seasonal phytoplankton concentration and sea surface temperature cycles of the Gulf of Mexico as determined by satellites. J. Geophys. Res. 96: 12645-12665.

17. Muller-Karger, F., R. Varela, R. Thunell, Y. Astor, H. Zhang, R. Luerssen and C. Hu. 2004. Processes of coastal upwelling and carbon flux in the Cariaco Basin. Deep-Sea Res. II 51: 927-943.

18. O'Reilly, J.E., Maritorena, S., Mitchell, B.G., Siegel, D.A., Carder, K.L., Garver, S.A., Kahru, M. and McClain, C. (1998). Ocean color chlorophyll algorithms for SeaWiFS. J. Geophys. Res., 103: 24,937-24,953.

19. Pitcher, KG.C. and Weeks, S.J. 2006. The variability and potential for prediction of harmful algal blooms in the southern Benguela ecosystem. In: Benguela: Predicting a large marine ecosystem, Shannon, V., Hempel, G., Moloney, C.L., Woods, J.D. and Malonotte-Rizzoli, P. (eds), Elsevier, The Netherlands, pp. 125-146.

20. Platt, T., and S. Sathyandranath, Oceanic primary production. Estimation by remote sensing at local and regional scales, Science, 241, 285-296, 1988.

21. Platt, T., Fuentes-Yaco, C., and Frank, K. (2003). Spring algal bloom and larval fish survival. Nature, 423: $398-$ 399.

22. Polovina, J.J., E.A. Howell, and M. Abecassis. 2008. Ocean's least productive waters are expanding. Geophys. Res. Lett., 35, L03618, doi:10.1029/2007GL031745.
23. Siegel, D.A., Maritorena, S., Nelson, N.B., Hansell, D.A., Lorenzi-Kayser, M. (2002). Global distribution and dynamics of colored dissolved and detrital organic materials. J. Geophys. Res. (Oceans), 107(12): doi:10.1029/2001JC000965

24. Stumpf, R.P., M.E. Culver, P.A. Tester, M. Tomlinson, and G.J. Kirkpatrick and others. 2003. Monitoring Karenia brevis blooms in the Gulf of Mexico using satellite ocean color imagery and other data. Harmful Algae 2: 147-160.

25. Stumpf, R., Fleming-Lehtinen, V. and Granéli, E., (2010). "Integration of Data for Nowcasting of Harmful Algal Blooms" in these proceedings (Vol. 1), doi:10.5270/OceanObs09.pp.36.

26. Thomas, A.C., M.E. Carr and P.T. Strub. 2001. Chlorophyll variability in eastern boundary currents. Geophys. Res. Letts. 28, 3421-3424.

27. Thomas, A.C., D. W. Townsend and R. Weatherbee. 2003. Satellite-measured phytoplankton variability in the Gulf of Maine. Continental Shelf Research 23:971989.

28. Thomas, A.C., D. W. Townsend and R. Weatherbee. 2004a. Erratum to "Satellite-measured phytoplankton variability in the Gulf of Maine" [Cont. Shelf Res. 23 (2003) 971-989], Cont. Shelf Res 24: 293-294.

29. Thomas A.C., P. T. Strub, M.E. Carr and R. Weatherbee, 2004b. Comparisons of chlorophyll variability between the four major global eastern boundary currents. Int. $J$. Remote Sensing 25: 1443-1447.

30. Tseng, C.-M., G.T.F. Wong, I.-I. Lin, C.-R. Wu and K.-K. Liu. 2005. A unique seasonal pattern in phytoplankton biomass in low-latitude waters in the South China Sea, Geophys. Res. Lett. 32, L08608, doi:10.1029/2004GL022111.

31. Uz, B.M., J.A. Yoder and V. Osychny. 2001. Pumping of nutrients to ocean surface waters by the action of propagating planetary waves. Nature 409: 597-600.

32. Vantrepotte, V., and Mélin, F. 2009. Temporal variability of 10-year global SeaWiFS time-series of phytoplankton chlorophyll a concentration. - ICES Journal of Marine Science, 66: 1547-1556.

33. Wilson, C. 2003. Late summer chlorophyll blooms in the oligotrophic North Pacific subtropical gyre. Geophys. Res. Lett. 30, 1942, doi:10.1029/2003GL017770.

34. Wilson, C. and D. Adamec. 2001. Correlations between surface chlorophyll and sea surface height in the tropical Pacific during the 1997-1999 El Nino - Southern Oscillation event, J. Geophys. Res., 106: 31175-31188.

35. Yamada, K., J. Ishizaka, S. Yoo, H-c Kim and S. Chiba. 2004. Seasonal and interannual variability of sea surface chlorophyll a concentration in the Japan/East Sea (JES). Progress in Oceanography 61, 193-211.

36. Yoder, J.A. and M.A. Kennelly. 2003. Seasonal and ENSO variability in global ocean phytoplankton chlorophyll derived from 4 years of SeaWiFS 
measurements. Global Biogeochem. Cycles, 17(4), 1112, doi:10.1029/2002GB001942, 2003.

37. Yoder, J.A. and M.A. Kennelly. 2006. What have we learned about ocean variability from satellite ocean color imagers? Oceanography 19: 152- 171.

38. Yoder, J.A., J.E. O'Reilly, A.H. Barnard, T.S. Moore and C.M. Ruhsam. 2001. Variability in Coastal Zone Color Scanner (CZCS) chlorophyll imagery of ocean margin waters off the U.S. East Coast. Continental Shelf Research, 21: 1191-1218.

39. Yoder, J.A., S.E. Schollaert and J.E. O'Reilly. 2002. Climatological phytoplankton chlorophyll and seasurface temperature patterns in continental shelf and slope waters off the Northeast U.S. coast. Limnol. Oceanogr. 47:672-682.

40. Yoder, J., Dowell, M., Hoepffner, N., Murakami, H. and Stuart, V., (2010). "The Ocean Colour Radiance Virtual Constellation (OCR-VC)." in these proceedings (Vol. 2), doi:10.5270/OceanObs09.cwp.96.

41. Yoo, S. and H.-C. Kim. 2004. Suppression and enhancement of the spring bloom in the southwestern East Sea/Japan Sea. Deep-Sea Res II 51: 1093-1111. 